\title{
Erectile dysfunction: The perspectives of patients and partners on counselling
}

\author{
JC Lee MD¹, DHC Surridge $\mathrm{DM}^{2}$, A Morales $\mathrm{MD}^{1}$, JPW Heaton MD
}

JC Lee, DHC Surridge, A Morales, JPW Heaton. Erectile dysfunction: The perspectives of patients and partners on counselling. J Sex Reprod Med 2002;2(1):11-15.

BACKGROUND: Many health professionals who deal with patients with erectile dysfunction (ED) vigorously promote the emotional concerns of the patient and the involvement of the couple in planning the management of ED. The importance of restoring penile erection as an isolated medical problem has been de-emphasized in recent years in favour of a more holistic approach to patient and partner. It is commonly accepted that support for the couple should enhance their satisfaction and compliance with therapy.

METHODS: A prospective study was conducted to assess the attitudes of the patient and his partner toward a global approach to the diagnosis and the treatment of ED. After the initial consultation, a random sample of 100 consecutive heterosexual patients was asked to return with their partners for a full psychiatric and psychological evaluation. Information was collected during the interview and in counselling sessions.

RESULTS: Although patients were asked to return with their partners, nearly 60 did not comply. In general, the attitude of the partner to the patient's ED was that it was the patient's problem, not hers. The partner's attitude to sexual activity was often either one of indifference or a preference for no further sexual intercourse. In the majority of cases, the couple was either unaware of emotional problems in themselves or in the relationship, or were not prepared to disclose them. Less than $20 \%$ of those who did disclose the emotional problems agreed to attend further counselling, and even fewer (9\%) did so. A persistent comment was that the availability of counselling did not affect the prime goal, which was restoration of penile function. In a considerable proportion (greater than $40 \%$ ) of patients, alcohol and other substance abuse was identified as an important cofactor in the genesis of ED. In all these cases, further counselling was offered, but less than $5 \%$ of the patients accepted.

CONCLUSIONS: Men with ED want to have a rigid penis. They and their partners show very limited interest in accepting help with relationship issues, general sexual issues and lifestyle issues (eg, smoking and alcohol), even if professional judgement and clinical evidence point to the major importance of these factors in influencing sexual outcomes.

Key words: Counselling; Erectile dysfunction; Partner attitudes; Penile rigidity

\section{Dysérection : le point de vue des patients et des partenaires sur les services de consultation}

HISTORIQUE : De nombreux professionnels de la santé qui rencontrent des patients atteints de dysfonction érectile (DÉ) recommandent énergiquement d'intégrer les préoccupations affectives du patient et la participation du couple à la planification de la prise en charge de la DÉ. Depuis quelques années, on accorde moins d'importance au rétablissement de l'érection pénienne comme problème médical isolé, pour favoriser une démarche plus complète auprès du patient et de sa partenaire. Il est communément accepté que le soutien du couple doive accroître la satisfaction et le respect du traitement.

MÉTHODOLOGIE : Une étude prospective a été effectuée pour évaluer les attitudes du patient et de sa partenaire face à une méthode globale de diagnostic et de traitement de la DÉ. Après la première consultation, un échantillon aléatoire de 100 patients hétérosexuels consécutifs ont été invités, en compagnie de leur partenaire, à subir une évaluation psychiatrique et psychologique complète. L'information a été colligée pendant l'entrevue et les séances de counseling.

voir page suivante

Departments of ${ }^{1}$ Urology and ${ }^{2}$ Psychiatry, and ${ }^{1,2}$ the Human Sexuality Group, Queen's University, Kingston, Ontario

Correspondence: Dr A Morales, Kingston General Hospital, 76 Stuart Street, Kingston, Ontario K7L 2V7.

Telephone 613-548-2424, fax 613-545-1970 


\section{COPYRIGHT PULSUS GROUP INC, - DO NOT COPY}

RÉSULTATS : Bien que les patients aient été invités à revenir en compagnie de leur partenaire, plus de 60 n'ont pas respecté cette directive. En général, face à la DÉ du patient, la partenaire trouvait qu'il s'agissait du problème du patient et non du sien. La partenaire était souvent indifférente quant à l'activité sexuelle ou préférait ne plus avoir de relations sexuelles. Dans la majorité des cas, le couple n'avait pas conscience des troubles affectifs personnels ou propres à la relation ou il n'était pas prêt à en parler. Moins de $20 \%$ de ceux qui ont divulgué leurs troubles affectifs ont accepté de poursuivre le counseling, et encore moins (9\%) l'ont fait. D'après un commentaire constant, la disponibilité du counseling ne changeait en rien le principal objectif : le rétablissement de la fonction érectile. Chez une proportion considérable (plus de $40 \%$ ) de patients, l'alcool et l'abus d'autres intoxicants étaient identifiés comme un important cofacteur de la genèse de la DÉ. Dans tous ces cas, un counseling supplémentaire a été proposé, mais moins de $5 \%$ des patients ont accepté de s'y plier.

CONCLUSIONS : Les hommes atteints de DÉ désirent retrouver un pénis rigide. Ces hommes et leurs partenaires se montrent très peu intéressés à accepter de l'aide en matière de relations, de sexualité générale et de mode de vie (p. ex., tabagisme et alcool), même si le jugement professionnel et les observations cliniques soulignent la grande importance de ces facteurs dans la performance sexuelle.
$\mathrm{E}_{\mathrm{s}}^{\mathrm{r}}$ rectile dysfunction (ED) is estimated to affect $10 \%$ to $50 \%$ of the aging male population (1). ED is a common manifestation of many disorders, including diabetes, cardiovascular disease, psychiatric disease and general lifestyle issues. For a variety of reasons, there is nonagreement as to whether the erections should be treated in isolation (phallocentric approach) or if ED should be addressed in a more comprehensive manner.

A psychogenic component has been recognized as a factor, cause and sequelae of ED (2-4). Attitudes toward ED have changed considerably in the past few decades. What was once thought to be a purely psychological problem (5) treated with counselling is now often considered to be the result of neurohormonal and microvascular imbalances. The urological community has taken much criticism for treating solely the 'vascular organ' and not the patient as a whole. There are advocates of a multidisciplinary approach to ED involving both a urologist, and a psychiatrist, psychologist or counsellor (5-8). However, in an era of resource limitations, this may no longer be feasible in most health care systems. In addition, with the advent of new, simpler, safe and effective therapies, the evaluation and treatment of ED is undergoing profound changes. Urologists are being forced to streamline their practices, depending on efficacy and patient desires.

Counselling as a treatment modality has been studied in the past. Its efficacy is not in question in the present study. However, no one has examined patient attitudes towards counselling as a treatment modality. Patient wishes are becoming more important as they are fundamental to compliance with therapy. Furthermore, partner issues are equally important because sexual activity involves both parties. The aim of the present study was to determine, in an objective manner, patient and partner attitudes toward psychological treatment as a modality for the treatment of ED.

\section{METHODS}

A group of 100 consecutive men presenting to the Human Sexuality Clinic, Kingston General Hospital, for an initial assessment participated in the study. All patients underwent a standard evaluation as previously described (9). This included a directed history, physical examination and blood work. All patients then agreed to be evaluated and treated by one of the research team's psychiatrists, David HC
Surridge. Patients were instructed multiple times to bring their partners to the psychiatric session.

The psychiatrist performed a full evaluative interview of the patient and/or the couple. This evaluation included obtaining patient demographics, past medical and/or organic history, past and current sexual history, lovemaking cycle, psychogenic factors, partner attitudes toward the ED and the couple's attitude toward counselling. During the interview, the patients were assigned a 'psychogenic rating'. This rating was a subjective score from 1 to 4 determined by the psychiatrist, based on the quantity of psychogenic factors and the qualitative effect that these had on the patient's ED and on his relationship with his partner (10).

All patients were offered follow-up counselling or psychotherapy. Those patients with high psychogenic scores, and/or significant psychosocial or psychiatric problems, such as depression and alcoholism, were strongly encouraged to pursue further psychiatric therapy. The patients' and the couples' desires for further therapy and compliance with such therapy were documented.

As the cohort consisted of 100 men, results involving the entire group are expressed in percentage terms. The Student's $t$ test was used in the analysis of results on the patients' awareness of the contribution of psychogenic factors to their ED.

\section{RESULTS}

The average age of the patients being assessed was $55.1 \pm 10.9$ years. They were all white, and the majority were married $(74 \%)$. One patient was single, while the remainder were in long term, monogamous relationships. The level of education of the patients was also examined because it was thought that this may have some effect on patient attitudes toward counselling. Approximately $50 \%$ of the patients had some form of postsecondary education (Table 1).

In the psychogenic ratings, no patient was given a score of ' $\mathrm{O}$ ' because all patients have psychosocial stressors in their daily lives; however, some stressors (eg, alcoholism and marital discord) had stronger effects on the $\mathrm{ED}$ and the relationships than others (eg, child care issues). The strength of the effect of the stressor on the ED and the relationships was the basis of the range of scores from 1 (lowest effect) to 4 (highest effect). The majority of patients $(63 \%)$ rated low in the nonorganic category, but 
TABLE 1

Level of education achieved by the 100 patients with erectile dysfunction

\begin{tabular}{lc}
\hline Level of education & Proportion of patients \\
\hline University & $17 \%$ \\
Technical college & $35 \%$ \\
Trade school & $6 \%$ \\
High school & $40 \%$ \\
Elementary school & $2 \%$ \\
\hline
\end{tabular}

TABLE 2

Distribution of psychogenic ratings (scored out of 4) for the $\mathbf{1 0 0}$ patients with erectile dysfunction

\begin{tabular}{lc}
\hline $\begin{array}{l}\text { Psychogenic } \\
\text { rating }\end{array}$ & $\begin{array}{c}\text { Proportion } \\
\text { of patients }\end{array}$ \\
\hline 1 & $38 \%$ \\
2 & $25 \%$ \\
Proportion of patients with low ratings & $63 \%$ \\
3 & $17 \%$ \\
4 & $20 \%$ \\
Proportion of patients with high ratings & $37 \%$ \\
\hline
\end{tabular}

$37 \%$ of the patients had a high psychogenic score (score of 3 or 4 ) as estimated by the psychiatrist (Table 2). Among the psychogenic stressors that were identified, marital problems and substance abuse were common (Table 3). Many patients had more than one stressor because they were not mutually exclusive.

Substance abuse (alcohol and illegal drugs) was a prevalent problem. Twenty-two per cent of patients matched the criteria outlined in the Diagnostic and Statistical Manual of Mental Disorders, fourth edition (11), for alcohol abuse. A further 26\% drank large volumes of alcohol daily; however, they did not satisfy all the criteria for an 'alcoholic' (Table 4). Significantly, only three of the 22 alcoholics $(13.6 \%)$ identified this factor as a problem in their lives. The majority felt that it had no effect on their relationship or any causal effect on their ED. Of the 'problem drinkers', none identified their alcohol consumption as a problem.

When patients were asked whether they felt that they had any psychosocial stressors in their lives, $48 \%$ felt that they had none. Forty-two per cent were aware of such factors, but refused intervention aimed at their resolution. Eight of 100 men felt that they had significant psychogenic factors for which they wanted help.

Of the 100 men in the study, only $43 \%$ brought their prospective partners to the second visit. This compliance figure is low, considering that they were requested repeatedly to attend with their partners; the importance of such a visit was explicitly indicated in detail and the service has no financial implications for the couple. Of the 43 partners who were interviewed in the absence of the patient,
TABLE 3

Characterization of identified stressors for the 100 patients with erectile dysfunction

\begin{tabular}{lc}
\hline Stressor & Proportion of patients \\
\hline Marital problems & $30 \%$ \\
Substance abuse & $27 \%$ \\
Emotional abuse & $13 \%$ \\
Psychiatric problems & $6 \%$ \\
Financial problems & $5 \%$ \\
Child care issues & $2 \%$ \\
Grieving problems & $2 \%$ \\
Infidelity issues & $2 \%$ \\
\hline
\end{tabular}

TABLE 4

Alcohol use by the 100 patients with erectile dysfunction

\begin{tabular}{lc}
\hline Alcohol use & Proportion of patients \\
\hline Alcoholic & $22 \%$ \\
Problem drinker & $26 \%$ \\
Social drinker & $29 \%$ \\
Nondrinker & $23 \%$ \\
\hline
\end{tabular}

$35(81.4 \%)$ indicated that the sexual dysfunction was solely 'his problem'. The partners of the patients were then asked about their attitudes toward further sexual activity with their partners. Twenty-three $(53 \%)$ partners of the patients were happy to continue having sexual relations with their partners. However, $25 \%$ were indifferent or were vehemently against any further sexual activity. The remaining $22 \%$ of partners were prepared to continue sexual activity but were without enthusiasm. Note that this question was asked during the joint (patient and partner) portion of the interview.

A comparison was then made between patients with a high psychogenic score ( 3 or $4 ; n=37)$ and those with a low score ( 1 or $2 ; n=63)$. Patients with a high score were more likely to be aware of psychogenic factors (59\% versus $41 \%$ ); however, this difference was not found to be significant $(\mathrm{P}<0.10)$. Patients with a high psychogenic score were less likely to bring along their partners (29.7\% versus 50.8\%). This difference was significant $(\mathrm{P}<0.03)$.

Finally, patients and partners (if present) were asked about their desire for further counselling. Eighty-seven per cent stated that they did not want any further intervention. The level of education attained did not influence the patients' interest in further counselling. They expressed unequivocally their exclusive interest in treatment aimed directly at resolution of the erectile problem. Of the $13 \%$ of patients who agreed to undergo further counselling, only nine were compliant. All of these nine patients had a psychogenic score of 4 . A frequent comment from the patients was that the availability of counselling did not affect the prime objective of a rigid penis. 


\section{COPYRIGHT PULSUS GROUP INC, = DO NOT COPY \\ DISCUSSION}

The present study is the result of the frustration of the team at the Human Sexuality Clinic in dealing with a population of patients with ED in whom emotional and frank psychiatric issues are prominent. Frequently, there were multiple psychosocial stressors or psychiatric diseases identified, which would have benefitted from some form of psychiatric intervention. However, patients were unwilling to accept psychiatric therapy and were noncompliant with followup, even when they agreed to treatment.

This patient cohort, presumably representative of the population of patients with ED treated at the Human Sexuality Clinic, exhibited multiple psychosocial stressors, including marital problems and alcohol abuse. The patients' perceptions of these problems were skewed. Many patients failed to recognize or admit the presence of a problem. Whether the psychogenic factors were pre-existing or whether they developed due to the ED was not a primary issue in the study. However, how patients perceived and dealt with their problems was paramount. As documented in previous studies (12), patients with substance abuse deny their problems and usually do not seek treatment for their disorder. Such was the case in the present study. Only three of 22 alcoholics felt that their drinking was a problem, and none of the problem drinkers accepted this as a relevant issue. Although they were made aware of the potential for adverse effects of alcohol abuse on their erectile function, as well as more significant health and relationship consequences, the patients discounted their importance.

The partners' attitudes were unexpected. It has been assumed generally that the partners are usually accepting and supportive of the patient and his ED $(13,14)$. Many investigators rightly advocate the active participation of the partner in the evaluation and treatment of the ED to enhance results (14-17). However, attendance of the partners at the counselling sessions was poor and may have been an indication of underlying, pre-existing marital problems within the couple. Of the $43 \%$ of partners who did attend, $81 \%$ felt that the ED was solely the man's problem. The relative indifference of the partner to future sexual activity was also alarming. Fifty-three per cent of partners were willing to resume future sexual activity, but this may be an overestimate because the patient was present when the question was asked. The inappropriateness of asking this question during the joint interview is evident now, but it provides an interesting insight into the divergent desires of couples. Previously, we assumed that partners are generally interested in regaining a full, active sex life, including intercourse. We may need to revise such an opinion in light of these findings.

We do not know to what extent the appointment with a psychiatrist deterred the partners from participating. Although the patients were clearly informed of the nature of the interview and the expertise of the interviewer in sexual issues, it is possible that the association of psychiatry with mental illness may have interfered with the partners' willingness to participate.
When comparing patients with a high psychogenic rating with those with a low rating, an inverse correlation in relation to the attendance of the partners for interview emerges. One of the most common problems in those with a high rating was marital discord. If a patient and partner are not getting along, then it follows that partners are disinclined to attend. In others words, these couples are caught in a vicious circle.

Eighty-seven per cent of patients and/or partners did not want additional therapy. The majority cited the fact that they were solely interested in penile rigidity. They felt that they had been referred to the urologist to have their problem 'fixed' and were not concerned with their overall well-being. Whether the attitudes are different among patients referred initially to a clinic with a different emphasis (nonurological) remains to be investigated. However, these patients had very little insight into their relationship and life stressors. Even when they did recognize the presence of these life stressors, they were not interested in seeking counselling. This is particularly remarkable given that such service is cost-free in the Canadian health care system. Equally surprising was the finding that the level of education (ie, postsecondary and beyond) made no difference to the patients' interest in pursuing additional counselling. The only encouragement was that all of the patients interested in further counselling had a psychogenic score of 4 . In other words, those who needed counselling most were, fortunately, the ones most likely pursuing it.

The role of psychiatrists or psychologists in the treatment of ED is not defunct. However, their roles will probably change. The new medications becoming available on the Canadian pharmaceutical market are currently changing the number of patients presenting to the urologist for the treatment of ED and the number who are successful in regaining penile rigidity. Once the recovery of erectile function takes place, major changes may occur in relationship dynamics. The present study showed that a large percentage of partners were either indifferent or unhappy about future sexual activity. These attitudes of the partners will undoubtedly present new conflicts in relationships with pre-existing problems. The couple may then be dealing with incompatible desires once the patient or partner no longer has the excuse of ED. Patients will also realize that despite having a rigid penis, their lifestyle issues (eg, alcoholism) still remain. It will be a fertile field of investigation to determine whether patients will accept dealing with such problems in a global way, or if the denial and the poor communication will perpetuate or even enhance the inadequate performance.

\section{CONCLUSION}

Despite being given ample opportunity and a cost-free service, patients do not want psychological therapy for their ED. They perceive that the only problem that needs to be addressed is the penile rigidity and not the array of lifestyle and health issues facing them. The partners are 


\section{PEEROMOM USE ONLY DO MOT COPY \\ COPYRIGHT PULSUS GROUP INC, : DO NOT COPY}

not necessarily willing participants in future sexual activity with the patients, and the majority of the partners feel that the 'sexual dysfunction' is solely his problem. These attitudes of the partners raise many serious issues. Penile rigidity can be restored, in many instances, with the increasing number of effective medications available for the treatment of patients with ED; however, this approach is of limited value in improving the emotional components of a more global problem. The role of counselling and psychotherapy will be fundamental in dealing with the relationship fallout when restored sexual function fails to resolve all of the difficulties in the relationship. However, at this point, it may be too late for such interventions to be effective for the couple.

\section{REFERENCES}

1. Feldman HA, Goldstein I, Hatzichristou DG, Krane RJ, McKinlay JB. Impotence and its medical and psychosocial correlates: results of the Massachusetts Male Aging Study. J Urol 1994;151:54-61.

2. Tiefer L, Scuetz-Mueller D. Psychological issues in diagnosis and treatment of erectile disorders. Urol Clin North Am 1995;22:767-73.

3. Smith AD. Psychologic factors in the multidisciplinary evaluation and treatment or erectile dysfunction. Urol Clin North Am 1988;15:41-51.

4. Barlow DH. Causes of sexual dysfunction: the role of anxiety and cognitive interference. J Consult Clin Psychol 1986;54:140-8.

5. Rosen RC, Leiblum SR. Treatment of sexual disorders in the 1990s: an integrated approach. J Consult Clin Psychol 1995;63:877-90.

6. Krauss DJ, Lantinga LJ, Kelly CM. In treatment impotence, urology and sex therapy are complementary. Urology 1990;36:467-70.

7. Kaplan HS. The combined use of sex therapy and intrapenile injections in the treatment of impotence. J Sex Marital Ther 1990;16:195-207.

8. Finkle AL. Sexual impotency: current knowledge and treatment. Urology 1980;16:449-52.

9. Morales A, Johnston B, Heaton JPW, Lundie M. Testosterone supplementation for hypogonadal impotence: assessment of biochemical measures and therapeutic outcomes. J Urol 1997;157:849-54.

10. Reid K, Surridge D, Condra M, Morales A. The psychological correlates of psychogenic impotence. Sex Disabil 1987;8:1-4.

11. American Psychiatric Association. Diagnostic and Statistical Manual of Mental Disorders, 4th edn. Washington: American Psychiatric Association, 1994.

12. O'Farrell TJ, Choquette KA, Cutter HS, Birchler GR. Sexual satisfaction and dysfunction in marriages of male alcoholics: comparison with nonalcoholic maritally conflicted and nonconflicted couples. J Stud Alcohol 1997;58:91-9.

13. Carroll JL, Bagley DH. Evaluation of sexual satisfaction in partners of men experiencing erectile failure. J Sex Marital Ther 1997;23:70-8.

14. Rouleau JL. Women's role in male sexual dysfunction. Acta Urol Belg 1989;57:177-81.

15. Intili H. Impotence and perceived partner support. Urol Nurs 1998;18:279-80.

16. Althof SE, Turner LA, Levine SB, Bodner D, Kursh ED, Resnick MI Through the eyes of women: the sexual and psychological responses of women to their partner's treatment with self-injection or external vacuum therapy. J Urol 1994;47:1024-7.

17. Speckens AE, Hemgeveld MW, Lychlama A, Nijehold B, van Hemert AM, Hawton KE. Psychosexual functioning of partners of men with presumed non-organic erectile dysfunction: cause or consequence of the disorder? Arch Sex Behav 1995;24:157-72. 